\title{
THE UNIVERSITY OF WISCONSIN-MADISON'S MASTER OF ENGINEERING IN PROFESSIONAL PRACTICE (MEPP) PROGRAM: THE ROAD TO QUALITY ONLINE GRADUATE ENGINEERING EDUCATION
}

\author{
Wayne P. Pferdehirt, Thomas W. Smith, Karen R. Al-Ashkar \\ Dept. of Engineering Professional Development \\ University of Wisconsin-Madison
}

\begin{abstract}
This case study explores several key design strategies behind the University of Wisconsin-Madison's Master of Engineering in Professional Practice (MEPP) program. Since its full-scale launch in 1999, this demanding graduate engineering degree program has achieved a graduation rate of more than $99 \%$ and has received major awards for instructional quality from the Sloan Consortium, the U.S. Distance Learning Association, and the University Continuing Education Association. This paper examines several key elements of the program's design and practical lessons learned through the program's first six years, during which 140 students have graduated from the two-year degree program. Distinctive elements of the program include: the program's cohort design; integration of weekly Webconferencing with asynchronous Web-based tools; optimization of course content and format for experienced, mid-career adults; and an annual on-campus residency. Program details are available at http://mepp.engr.wisc.edu.
\end{abstract}

\section{INTRODUCTION}

The Master of Engineering in Professional Practice (MEPP) was launched by the University of Wisconsin-Madison in 1999, following five years of planning and development, to help mid-career engineers become more effective leaders of technical teams and projects. An alternative to an MBA or traditional MS degree, MEPP provides the engineering, management, computer, and communications skills for today's global business environment. Providing this curriculum online brings new students to the university from major corporations, businesses, and government agencies. Schedule and travel conflicts prevented most of these engineers from previously pursuing graduate studies. MEPP students progress through the two-year program as a stable cohort, building supportive relationships. In post-graduation surveys, alumni point to the cohort as a key factor in the quality of their learning and success [7, 4]. Adult working engineers can participate in MEPP from anywhere in the world. Students are on campus only one week per year, in late August, for a group residency. All other studies can be performed at a distance, wherever the student lives or works, or wherever his or her travels take them.

MEPP students are typically mid-career engineers working full time, typically at demanding positions with significant travel requirements. Applicants to the program must have at least four years professional engineering experience; most have five to 30 years of experience and represent all engineering disciplines.

Detailed information regarding the program, including curriculum, faculty and admission requirements, is 
available at http://epdweb.engr.wisc.edu/mepp/.

\section{MEASURING PERFORMANCE WITH THE SLOAN-C PILLARS OF QUALITY}

The Sloan Consortium's five pillars of quality provide a helpful framework for developing and assessing quality in distance learning. The five pillars include: access; student satisfaction; learning effectiveness; faculty satisfaction; and cost effectiveness and institutional commitment. Using these pillars as criteria, the Sloan Consortium selected University of Wisconsin's MEPP degree program to receive its 2004 Most Outstanding Online Teaching and Learning Program Award. Evidence of MEPP's performance relative to the pillars of quality follows.

Access: Since 1999 MEPP has graduated 140 mid-career engineers from leading engineering employers across North America. 95\% of students have completed the program within two years and $97 \%$ within three years, far exceeding norms for graduate degree completion, whether on or off campus. MEPP's Web-based, portable format has enabled mid-career engineers to overcome previous barriers to graduate education.

Student Satisfaction: Student satisfaction is measured via an end-of-semester evaluation of each course and an evaluation of the entire program at graduation [1]. Course evaluations consistently exceed 4.0 on a 5.0 scale. Students also complete an end-of-program evaluation at graduation that measure satisfaction with the overall program. As part of this evaluation, graduates rate the importance of each MEPP course. These ratings by each of the five graduating classes to date are shown in Table 1 . The ratings indicate that all MEPP courses most recently received a score of at least 4.24, and upward trends in ratings reflect continuous improvement efforts.

\begin{tabular}{|c|c|c|c|c|c|c|c|c|c|c|}
\hline YEAR & 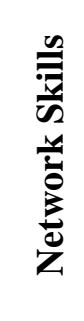 & 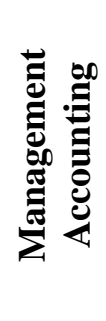 & 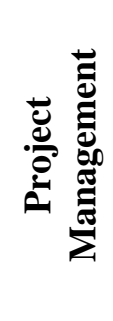 & 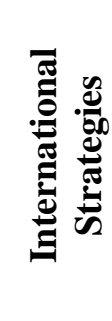 & 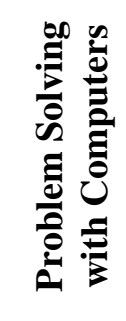 & 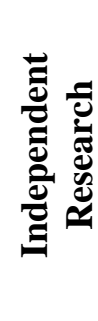 & 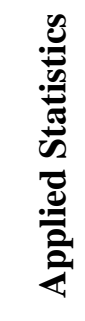 & 预 & 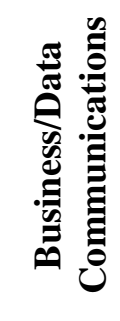 & 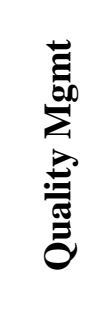 \\
\hline 2001 & 4.00 & 4.26 & 4.47 & 4.26 & 4.00 & 3.79 & 3.68 & 4.53 & 4.47 & 3.74 \\
\hline 2002 & 4.55 & 4.86 & 4.82 & 4.64 & 4.73 & 4.27 & 4.73 & 4.73 & 4.18 & 4.14 \\
\hline 2003 & 4.37 & 4.58 & 4.68 & 4.26 & 4.63 & 4.21 & 4.84 & 4.74 & 4.32 & 4.58 \\
\hline 2004 & 4.71 & 4.81 & 4.95 & 4.71 & 4.67 & 4.24 & 4.71 & 4.76 & 3.67 & 4.52 \\
\hline 2005 & 4.62 & 4.67 & 4.90 & 4.57 & 4.38 & 4.52 & 4.81 & 4.67 & 4.24 & 4.71 \\
\hline
\end{tabular}

Table 1: Rating of Importance of MEPP Courses by Students at Graduation

Learning Effectiveness: MEPP's approach to online education focuses on interactivity, helping students connect more meaningfully with faculty, enabling work on team projects, and building on the knowledge and experience that adult students bring [1]. MEPP uses a blend of asynchronous and synchronous Webbased tools that support group work and an interactive learning community [2]. MEPP uses a rigorous evaluation system throughout the program and beyond to assess learning effectiveness [3]. 100\% of 
students report significant professional development during the program and 53\% report a promotion or salary increase that they attribute to MEPP. In the program impact survey, graduates and co-workers reported the significant improvements in taking risks and accepting responsibility, leading change efforts, demonstrating project management skills, and understanding business goals and their impact on engineering decisions.

Faculty Satisfaction: Faculty work closely with an instructional designer to ensure that courses are problem-based and engaging to experienced engineers [4]. As evidence of satisfaction, MEPP faculty are developing a new online ME degree and only one faculty member has chosen to discontinue teaching in the program over the past six years. Faculty enjoy the opportunity to teach highly motivated students who bring interesting applied experience and access to fascinating projects that can be used as part of the online classroom.

Cost Effectiveness and Institutional Commitment: MEPP is completely self-sustaining financially, supporting itself from tuition and fees and requiring no additional funds from the university. From the beginning MEPP developed a realistic business plan and initiated a new uniform tuition pricing for instate and out-of-state students. The program's investment in instructional design, course preparation, student support and administration has resulted in a high completion rate and positive impact in the workplace, thus increasing the cost-effectiveness of the investment by students and employers $[4,5]$. Courses emphasize immediate application of learning to work, and course projects draw upon students' real projects from the workplace. Employers see immediate benefits of the MEPP curriculum on students' performance, enhancing their support for students' studies.

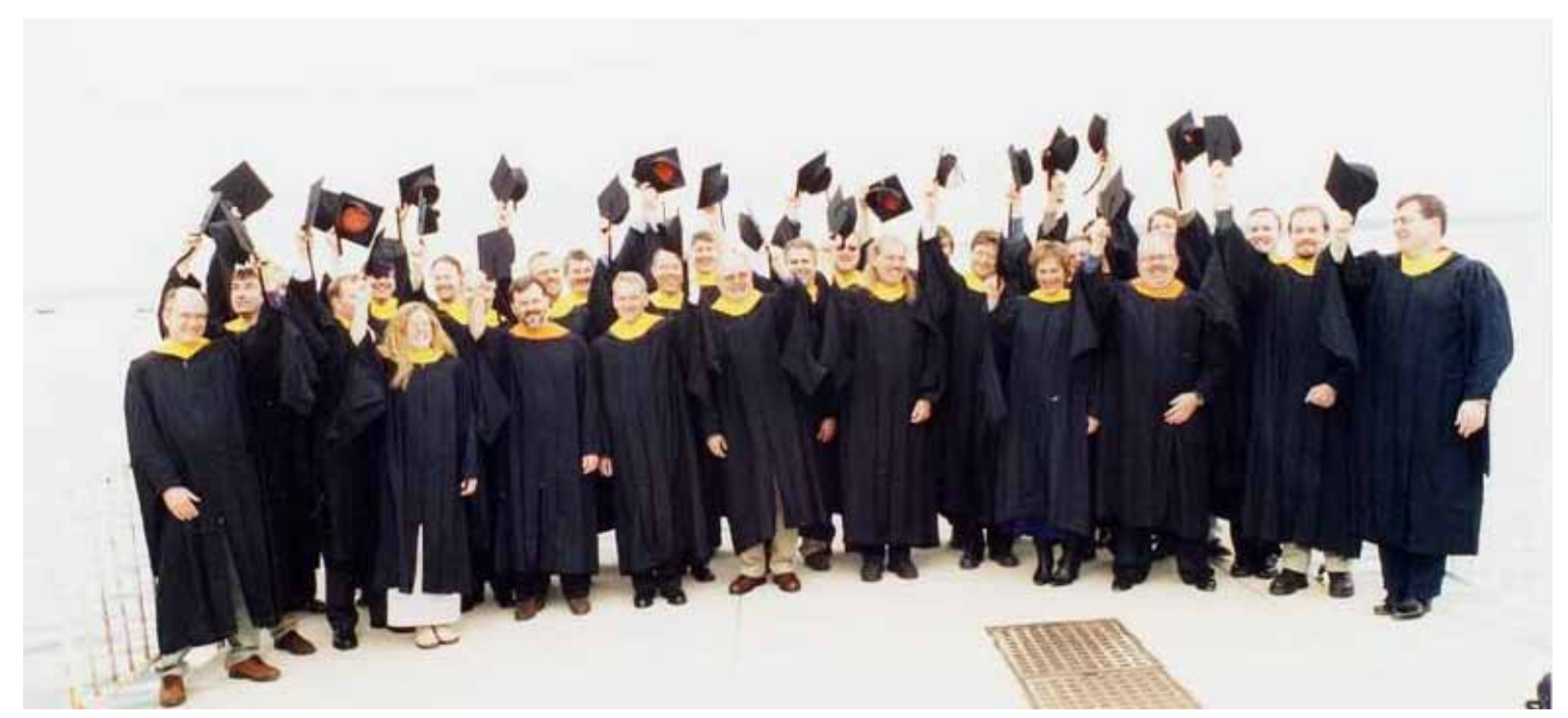

Figure 1: MEPP Graduates Love Asynchronous, Anywhere Learning but Synchronous, Face-to-Face Celebrations!

\section{KEYS TO SUCCESS}

\section{A. The Right People on the Bus}

In Good to Great, author Jim Collins explores the question of what practices and principles has helped "good" organizations become "great." Collins’s research [6] shows that leading organizations "first got the right people on the bus, the wrong people off the bus, and the right people in the right seats-then 
they figured out where to drive it." Having the right people on the bus, and having them actively engaged in setting the course, has been critical to MEPP's success. Since its early planning efforts, MEPP has enjoyed broad, bottom-up ownership by faculty, as well as the department chair and dean of engineering. Instructors have been willing pioneers, not reluctant foot-draggers assigned by top-down edict. Most of the instructors in the program are tenured senior faculty who bring well-established credibility on and off campus. Staff are all highly capable professionals who are enthused about building a new educational model to better serve the needs of mid-career engineers, who comprise the core focus of the UW-Madison Department of Engineering Development. The high degree of personal investment, competence, and credibility by faculty, key administrators, and staff has been crucial in the group's ability to have effective low-beam and high-beam vision as they collectively navigate the program's course.

\section{B. A Curriculum that Engineers and Their Employers Value}

The MEPP curriculum was developed as a result of an extensive survey of mid-career engineers and engineering employers and a review of relevant engineering education literature. Courses and their content were developed to meet the specific needs of mid-career engineers seeking to grow as technical leaders. Because all students must have at least four years of professional experience and most have substantially more, courses are able to tap into students' actual work projects for team and individual homework assignments, and for applied discussion of tools and concepts, creating a rich, engaging learning environment. Examples of recent MEPP students and the rich experience they bring to the online classroom include: several Harley-Davidson engineers who designed the drivetrain for Harley's innovative V-Rod motorcycle; NASA and vendors' engineers responsible for space shuttle power systems and safety; and a manager of information systems for the National Security Agency.

\section{Highly Effective, Cohort-Based Learning Community}

All graduates complete an evaluation of the entire MEPP program at graduation. When asked an openended question about the strengths of the program, the most-often mentioned feature is the program's cohort-based design. MEPP students progress through the MEPP curriculum as a stable cohort, building strong, supportive relationships along the way. The cohort model facilitates collaboration on team projects and knowledge sharing and contributes to high student satisfaction [7]. Within the fixed curriculum, students customize their learning by choosing course projects that help students achieve their self-defined learning goals for their MEPP studies.

\section{Evaluation and Continuous Improvement}

MEPP faculty, staff and students actively support a culture of continuous improvement. From the beginning, MEPP has emphasized the need to collect evaluation data to improve the program. All courses are run as pilots with small groups before their first full-scale class to debug the content and prepare the instructor. Pilot test participant evaluation data is used to fine-tune each course prior to full-scale offering. Once offered full-scale, student evaluation data is collected at the end of each course and used to plan revisions for the next offering. MEPP also administers a student completion survey to assess graduates' overall impressions. Program evaluation also includes a post-graduation program impact survey of alumni, their employers and family members to measure changes in graduates' skill domains addressed by program learning goals. MEPP models continuous improvement for students by visibly using results of these surveys to improve course design, program curriculum, and instructional methods. 


\section{E. Instructional Design Optimized for Adult Distant Learners}

MEPP's course design focuses on using the online classroom as the door to a highly interactive, collaborative shared world of learning, rather than a room at the end of an information pipeline. Program design focuses on facilitating meaningful student-instructor and student-student learning interactions [4, 8]. Through online discussions, Webconferences and group projects, MEPP students appreciate the opportunity to have learning windows open to 29 other engineering organizations and see how engineering and project management is really practiced within peer organizations [9].

\section{F. Problem-Based Learning}

Instructional design of all MEPP courses emphasizes problem-based learning, collaboration and authentic real-world applications. Problem-based learning accomplishes learning through practical design challenges, case studies and design projects [8]. Students see the value of their learning, stay engaged and motivated, and experience a high degree of learning transfer.

\section{G. Effective Blending of Instructional Formats}

MEPP intentionally uses a mix of synchronous and asynchronous learning formats, which complement each other in achieving learning objectives for each course [10]. Web-based asynchronous discussions are supplemented with textbooks, instructor-developed study guides, and CDs/DVDs, as well as weekly Webconferences and an annual one-week residency. MEPP students easily participate in Webconferences from any location anywhere in the world. Students are able to conduct Webconferences with each other any time of the day or night to work on group projects or conduct a group study session. Any document or application on any student's computer can be shared in real time with other team members, facilitating highly effective collaboration. When selecting the formats to be used, the focus is on using the most effective method to facilitate the intended interaction and collaboration.

\section{H. All Courses Taught by Committed Senior Faculty with Industry Experience}

MEPP employs senior faculty from several departments in the UW College of Engineering, as well as senior faculty from other institutions. All faculty teach in the program by their own choice, and all have significant experience working in industry. In evaluations students consistently report high satisfaction with the accessibility and responsiveness of faculty.

\section{Proactive Support of Students}

MEPP takes a proactive approach to anticipating students' needs and in intervening early when students' progress is flagging [11]. Faculty and a program-dedicated counselor closely monitor students' progress and contact students by e-mail or phone if progress is not sufficient. Instructors, the program counselor and the program director are provided biweekly statistics on student online activity to quickly identify students who are falling behind and initiate a note or call to explore why. These personal reminders, plus encouragement by fellow cohort members, make it impossible for students to simply "disappear" and keep them on pace with their classmates. 


\section{LESSONS LEARNED}

\section{A. True Excellence is Achievable in Web-Based Graduate Engineering Education.}

MEPP was UW-Madison's first Web-based degree program. As such, the program was understandably met with considerable skepticism by campus faculty. The program's success, documented in evaluations by students, alumni, and external reviewers has significantly improved the perception by many faculty of the quality that can be achieved in Web-based education. Similarly, as more employers have experienced concrete benefits from the MEPP education their employees have received, they too decrease their biases against Web-based education and become better-informed consumers of continuing education of all types $[12,13]$.

\section{B. What Matters Most to Students: Curriculum, Faculty, Supportive Learning Environment.}

It all comes back to fundamentals. When alumni were recently interviewed and asked what they most value about MEPP, the great majority of replies could be classified as either: (1) curriculum; (2) knowledgeable and responsive faculty; or (3) a supportive learning environment. The curriculum simply has to deliver the goods to the target audience. Alumni are the best judges of whether curriculum expectations and promises were met [14, 15] With respect to faculty, essentials include expertise, a genuine commitment to sound pedagogy, and a genuine commitment to understanding and responding in a timely manner to students' needs. MEPP faculty are expected to check course web sites at least daily and to reply to student questions within 24 hours, even if the initial reply is a promise to follow up at a later time. A supportive learning environment is built through cohort-based collaborative learning supported by proactive staff and faculty.

\section{The Cohort Model has been Even More Important than Expected.}

Research supported the use of a cohort learning model to best enable student success $[1,7]$. Feedback by MEPP graduates consistently underscores the critical importance of this program feature in enabling students to achieve such a high graduation rate. Inevitably, each student will reach some point of low motivation during the two-year program. Because students take each course together, they get to know each other well, enabling trust and deeper sharing of experiences and insights. A MEPP Community web site enables students to talk about any timely non-course topic. Students share family and work news, help each other troubleshoot hardware and software frustrations, and share the latest hurdles to staying on track. Other members of their cohort, perhaps members of the other Class, or even alumni, offer encouragement, building positive accountability and a culture of success.

\section{Connect the Nerves with the Right Muscle to get the Job Done.}

Nothing beats concerned responsiveness by faculty and staff in achieving student satisfaction. An important organizational principle is to keep services as close to the action as financially sustainable. It is vitally important to cultivate personal investment by support staff by enabling them to feel students' pain and joy [16]. Staff who provide student support need to be close enough to the action to see early signs of difficulty and have the authority and means to initiate proactive help. Within MEPP, the annual residencies build and reinforce personal connections between staff, students, and faculty. At monthly staff meetings, a regular agenda item is a temperature check on current courses to identify any ways that staff can better help faculty and staff address any current problems. 


\section{E. Effective Online Teaching takes a Willingness to Learn and Adapt by Instructors.}

Key adaptations include: having all course materials ready before the semester begins; tapping the expertise and support of an instructional design team; learning to interact effectively in a world without body language; and adjusting to the $24 / 7$ world. A program instructional designer works with each instructor to clarify course learning objectives and to help identify the most effective blend of formats and tools to achieve those objectives. Prior to introducing courses to matriculated students, each MEPP course was offered in a full-semester pilot mode to off-campus engineers enrolled as non-degree students. This approach allowed course design to be refined, while providing a valuable low-pressure opportunity for MEPP faculty to adapt to online teaching. After this initial experience, which was the first online teaching experience for most MEPP faculty, they were especially open to learning from the instructional design team about how to improve course design and execution. At MEPP faculty meetings, held via webconference, faculty regularly share tips, insights, and plans for improving their courses. In adjusting to the 24/7 world of online learning, instructors need to regularly monitor course discussion forums, establishing an engaged and caring presence. Instructors who try to put the course on autopilot for more than a few days can quickly quench students’ meaningful engagement in course discussions.

\section{F. Instructional Format and Technology must be Selected and Designed to Support Learning Interactions.}

Too often, programs become locked into using a particular tool/format before fully understanding the limitations and most appropriate uses of the tool/format as part of a blended design. Technology supporting distance learners must be reliable, robust, and flexible. Sound instructional design is far more important to learning effectiveness than are the bells and whistles. Match each tool to its most effective use. For example, asynchronous elements for individuals such as readings, recorded presentations, homework problems and research, are best for focused, self-directed learning. Asynchronous formats for groups, such as online threaded discussions, are best for engaging students in discourse, debate, facilitation and synthesis. Synchronous formats for groups, such as webconferences, are excellent at supporting real-time collaboration and problem-solving. Finally, occasional face-to-face interactions, such as MEPP's annual one-week residency, build relationships, re-energize students, help students connect more solidly with the university, and provide opportunities to conduct labs and site visits.

\section{G. The Road to Program Sustainability is Built with Consistent Investment in Quality.}

MEPP is financially self-supporting. It was designed from its inception to be a high-quality, low enrolment program that would pay all of its capital and operating costs from tuition revenues. The requirement that the program live or die on its performance, provides compelling incentives to achieve quality in each of the areas defined by the Sloan-C five pillars.

\section{Student Satisfaction is Critical to Recruitment of New Students.}

Making clear commitments and then consistently meeting and exceeding them is the best strategy for building a strong foundation for student recruitment efforts. For the incoming MEPP class, 16 of 32 students are from previously represented employers. Alumni, genuinely enthused about the quality of their education, are eager to tell colleagues about the program, ensuring strong applications and reducing recruitment costs. 


\section{Faculty Satisfaction Reduces Turnover and Enhances Political Support.}

Faculty turnover is costly, entailing course adaptation/redevelopment, faculty training, and increased staff support. Faculty who sense a serious commitment to quality-through the program's approach to instructional design to the salary support they are provided-build a strong personal investment in the program's future.

\section{Reliable Access Enables the Program to Recruit the Students We Want.}

They are busy, successful engineers with a high workload. An accessible program with a reliable and efficient platform and a high level of support is necessary for them to succeed.

\section{Learning Effectiveness Keeps the Students Going.}

The motivation from instant application of course principles is critical to student retention.

\section{Cost Effectiveness is Achieved by Delivering the Highest Value.}

The greatest investment by adult, professional students like those in MEPP is their time. As mid-career professionals working full-time (typically 50+ hours/week) jobs with frequent travel requirements and demanding family commitments, course content and delivery must make every study hour effective and efficient. Like the typical employer represented in MEPP, we commit to delivering the best value, not the cheapest product.

\section{H. Systematic Review and Application of Evaluation Data Drives Continuous Improvement.}

In his review of good organizations that became great, Collins [6] states that when you "start with an honest and diligent effort to determine the truth of the situation, the right decisions often become self evident." He emphasizes that any organization that aspires to greatness must be able to face the brutal facts of any situation. Principles of continuous improvement emphasize that what gets measured gets attention and gets improved. Within MEPP, a team that includes the instructor, the instructional designer, and a course manager review student and instructor feedback at the end of each semester, and develop a plan and schedule for improving the course prior to its next offering. Evaluations of the overall program are reviewed at a faculty meeting and at an advisory committee meeting to identify desired changes in program design and curriculum. Students see changes that occur as a result of their feedback, and, therefore, participate actively and thoughtfully in evaluation surveys.

\section{CONCLUSION}

The Master of Engineering in Professional Practice program at the University of Wisconsin-Madison has established a track record of providing world-class education via Web-based methods to mid-career engineers. The program provides firm evidence to engineering educators that excellence in online graduate education is achievable with careful attention to: curriculum; faculty selection, training and support; instructional design; and student support.

The authors would be glad to provide further information to other educators about program design, program and course evaluation instruments, or other elements of interest. 


\section{REFERENCES}

1. Gibson, C. C. Online learning: From high tech to high touch. In G. Kearsley (Ed.), Online Learning: Personal Reflections on the Transformation of Education. Englewood Cliffs, NJ: Educational Technologies Publications, 2005.

2. Pferdehirt, Wayne. Designing a web-based graduate degree program optimized for adult professionals learning at a distance. In Using Distance Education Technologies: Effective Practices University of Wisconsin-Extension, 2002.

3. Pferdehirt, Wayne. Integrated Assessment System for Courses, Overall Program and Post-Program Career Impacts. In Effective Practices (online), Sloan Consortium, August 2004.

4. Moore, M. G. and G. Kearsley. Distance Education: A Systems View, 2nd ed. Canada: Walworth Publishing, 2005.

5. Rumble, G. Modeling the costs and economics of distance education. In M. G. Moore and W. G. Anderson (Eds.), Handbood of Distance Education. Mahway, NJ: Lawrence Earlbaum Associates, 2003.

6. Collins, Jim. Good to Great: Why Some Companies Make the Leap... and Others Don't._New York, NY: HarperCollins Publishers, 2001.

7. Caffarella, M. Planning Programs for Adult Learners: A Practical Guide for Educators, Trainers, and Staff Developers. San Francisco: Jossey-Bass, 1994.

8. Naidu, S. Designing interaction for e-learning environments. In M. G. Moore and W. G. Anderson (Eds.), Handbook of Distance Education. Mahwah, NJ: Lawrance Earlbaum Associates, 2003.

9. Shearer, R. Instructional Design in Distance Education: An Overview. In M. G. Moore and W. G. Anderson (Eds.), Handbook of Distance Education. Mahwah, NJ: Lawrance Earlbaum Associates, 2003.

10. Kearsley, Greg. MEPP: A case study in online education. The Technology Source, January/February 2002.

11. Al-Ashkar, Karen. Support for students at a distance: Is technology enough? Proceedings of 2000 ASEE Annual Conference and Exhibition, Session 1322. American Society for Engineering Education Annual Conference, 2000.

12. Martin, Courtney Porter. Online alternative to an MBA. Prism, American Society of Engineering Education, September 2001.

13. George, Tracy. A wired education: How do electronic diplomas compare to traditional sheepskins? IIE Solutions, Institute of Industrial Engineers, September 2001.

14. Savoye, Craig. "Where in the World is My Student?” Christian Science Monitor, July 17, 2001.

15. Davis, Rachel. Engineers choose a degree of distance. Engineering Times, National Society of Professional Engineers, May 2002.

16. Schooley, Claire. The personal touch: It still has a place in e-learning. IdeaByte, Giga Information Group, October 2001.

\section{CREDITS}

The authors thank the many faculty and staff members whose creativity, passion and commitment have provided MEPP students a truly exceptional education. Program faculty and staff, in addition to the authors of this paper, include: Lauranne Bailey, Stacey Binder, James (Jake) Blanchard, Darryl L. Craig, Bruce Elbert, Conrad Fung, Chere Campbell Gibson, Donald E. Hanna, C. William Ibbs, Willis F. Long, Christine Grohowski Nicometo, Philip R. O’Leary, John T. Quigley, Nancy Rebholz, Rose Richgels, Paul Ross, Donald R. Schramm, Amy Shenot, Harold J. Steudel, and John Stremikis, We also gratefully acknowledge the extremely valuable instructional design expertise provided in the earlier years of the program by Greg Kearsley and Dan Coldeway. 


\section{AUTHORS}

Wayne P. Pferdehirt is the director of the MEPP program. Wayne also serves as director of Distance Degree Programs for the College of Engineering, working with college departments to develop, deliver and improve Web-based graduate degree programs. Wayne is a frequent speaker on Web-based continuing education for engineers. He has a BS in engineering from Carnegie Mellon University, and an MS in civil engineering with an emphasis in regional planning from Northwestern University.

Thomas W. Smith is director of telecommunications programming in the Department of Engineering Professional Development. He currently directs a series of short courses in telecommunications and distance education. He has been instrumental in the development of the University's audiographic teleconferencing and satellite communications capabilities. For this work he received the UW-Extension Award for Excellence and national awards from Telecom and ASEE. He has written more than 30 papers and articles on telecommunications and distance education and is a frequent speaker on this topic in the United States and Europe. He received his BS degree from Dartmouth College and MS degree from the University of Wisconsin-Madison.

Karen R. Al-Ashkar is the student advisor for the MEPP program. One of her roles is to listen to student concerns and issues and seek resolution when concerns conflict with academic performance. She chairs the MEPP Admissions Committee and is the point-of-contact person for applicants and students. Karen has been counseling adult students since 1991 and working with students at a distance since 1994. She has a BA in clinical chemistry and an MA in counseling. She is completing a PhD in distance education. 